\title{
Case study on Educational Effects for University Students of Their Out-of-Curriculum Project Activities
}

\author{
Makoto Hasegawa \\ Dept. Global System Design \\ Chitose Institute of Science and Technology \\ Chitose, Hokkaido, Japan \\ hasegawa@photon.chitose.ac.jp
}

\begin{abstract}
The out-of-curriculum project team organized by university students has been actively engaged in science promotion activities in local region over 10 years. These activities can provide the students with various Project-Based-Learning experiences and actually work as Active-Learning style education scheme. Although numerical evaluation is difficult, it can be considered that the activities of this student project team exhibit certain educational effects for the student members.
\end{abstract}

Keywords - active lerning; project-based-learning; student project; out-of-curriculum

\section{INTRODUCTION}

Active involvement of university students in learning has been strongly required worldwide, and the term "active learning" seems to become buzzword. However, enhancing students' motivation for participation into active-learning style education activities is not easy. When a student group include both highly-motivated members and poorly-motivated members, it is often difficult to realize satisfactory achievement.

The out-of-curriculum student project team "Rika-Kobo", organized by mainly undergraduate students, has been actively engaged in various activities for over 10 years, mainly for the purpose of promoting interests of children and other generation in local region into science and engineering [1-5]. The activities are warmly welcomed in the local region and their good reputation leads to the fact that the total number of their activities for each year become at around 60-70 recently and will exceed 70 for the Japanese fiscal year 2014.

The most important reason for such successful results is believed to exist in the fact that the activities of this student project team are out-of-curriculum [4]. The student members are involved in the activities not for the purpose of obtaining any credits nor improving their GPA scores, but instead voluntarily involved. In other words, the student members always have high degrees of internal motivation, and thus, the quality of their activities is in general high. Based on such facts, the author proposes that certain merits should be found in out-of-curriculum activities to be performed by university students in terms of educational effects for them.

In this paper, the activities of this student project team is introduced.

\section{CURRENT ACTIVITIES OF THE PROJECT TEAM}

Since the project team is out-of-curriculum, anyone who are interested in can voluntarily join the team anytime, irrespective of their majors nor grades. Typical situation is such that new members are likely to join the team when they enter the university as fresh persons, but some may join at later timing. Most of the student members are likely to continue their activities until their graduation. As a result, the number of student members of the project team is usually 20 to 30 from fresh persons to seniors, and sometimes postgraduate (Master course) students may remain active in the team.

Although this is not included in the official educational curriculum, university administration provides the project team with annual financial support to cover expenses. In addition, one laboratory room is available dedicated to daily activities of the project team. Fig.I exhibits some photos showing the dedicated laboratory room and actual daily activities. As describing later, the total number of activities are quite high, and therefore, the student members effectively utilize several white board for schedule managements.
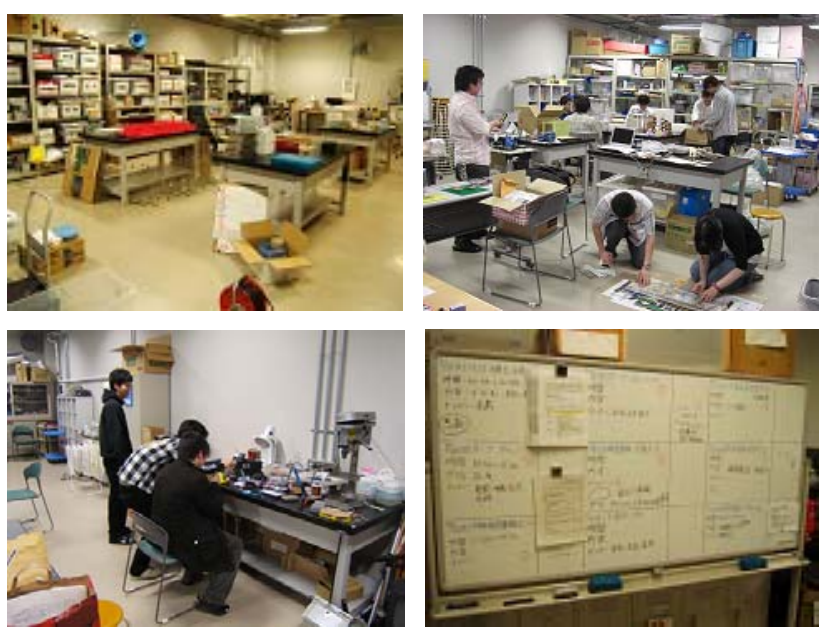

FIGURE I. SOME PHOTOS SHOWING THE DEDICATED LABORATORY ROOM FOR THE PROJECT TEAM AND DAILY ACTIVITIES IN THE LAB ROOM 


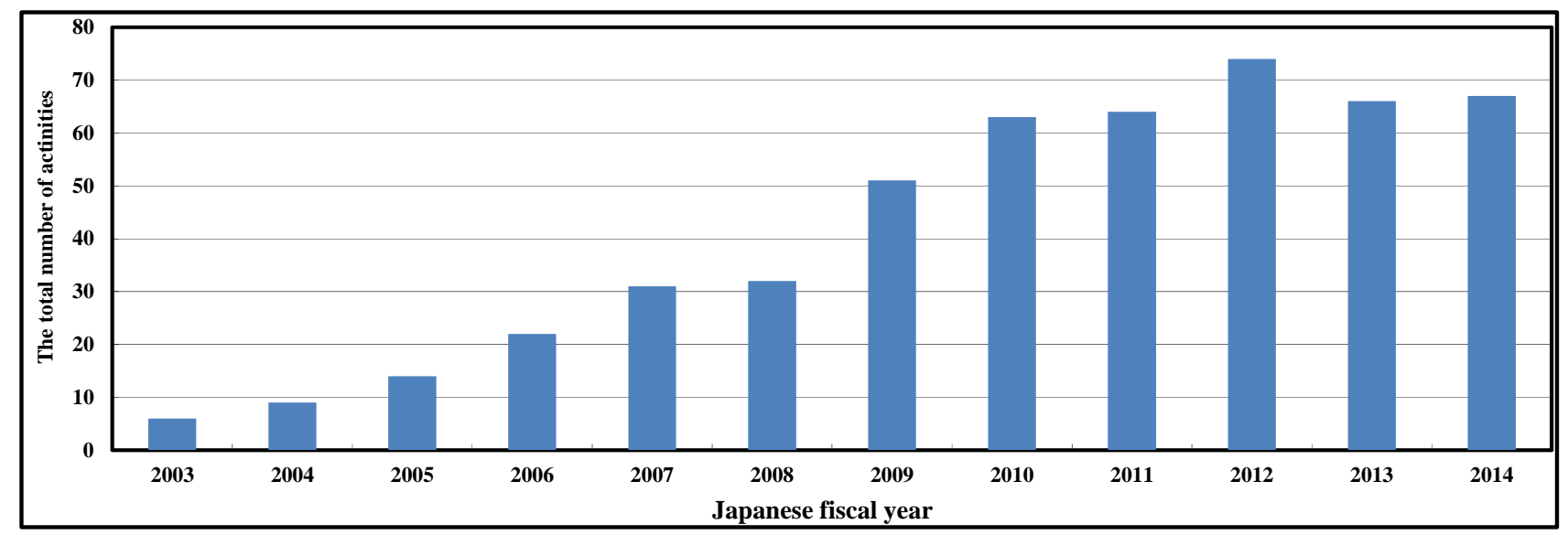

FIGURE II. THE TOTAL NUMBER OF ACTIVITIES FOR EACH JAPANESE FISCAL YEAR (the number for the year 2014 has been counted up to Dec.31)

Fig.II shows the total number of activities performed by the student project team for each Japanese fiscal year (from April 1 to next year March 31). Please note that the number for year 2014 was counted up to December 31, 2014. This chart clearly indicates significant increase in the number of activities. The total number of the activities to be performed for Japanese fiscal year 2014 is expected to reach 76, which will mark the new high record.

Each of these activities is mainly based upon request from local various organization, including elementary school, junior high school, science museum and other social education facilities, Parent and Teacher Association of local schools, and so on. Significant increasing trend indicates that the activities of the student project team can earn certain good reputations and warmly welcomed in the local regions.

Activities to be performed by the project team can include, for example, the following several categories.

1) Science experience classes in local schools. The student project team has opportunities for performing science experimental classes at several local schools. More specifically, at two of local elementary schools, the project team performs a series of three science experimental classes for the 5th grade and 6th grade over the last 10 years. In addition, at one local junior-high school, the team also performs classes once a year for 7 th grade.

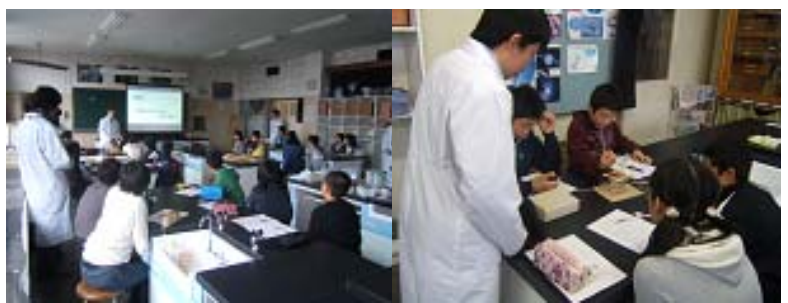

FIGURE III.

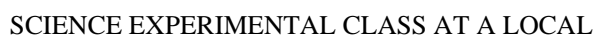
ELEMENTARY SCHOOL

As an example, Fig.III shows some photos of such a science experimental class at the local elementary school. One student acts as a teacher for proving the whole class with general explanation. The other members act as instructors for respective small groups of children and provide explanations and guidance on experimental procedures in detail. The topics of each experimental classes are not directly related to the subject-matters to be taught in science classes of elementary schools, and include spectrum of light, sunset colors, optical communication, air pressure, and electricity. Main purposes of these experimental classes are promotion and enlightenment of children's interests to various field of science and engineering.

2) Science classes at other local educational facilities. Similar science experimental classes are also performed at other local facilities such as a local science museum and children's houses, as shown in Fig.IV..

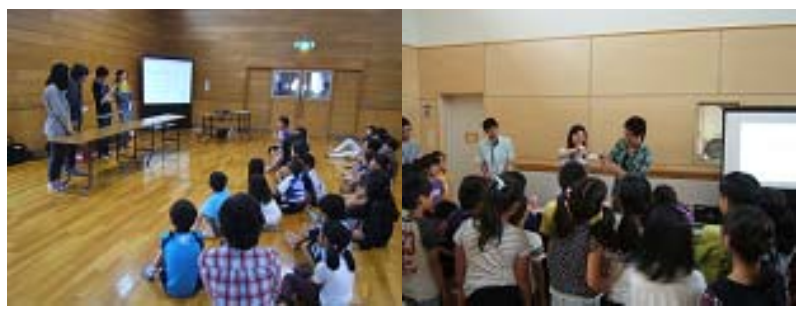

FIGURE IV. SCIENCE EXPERIMENTAL CLASS AT A LOCAL EDUCATIONAL FACILITY

3) Participation to various events. The project team is often invited by local organizations to participate in various events both indoors and outdoors. In response to such invitations, science experiment demonstrations as well as science experiment classes are performed under various situations, as shown in Fig.V. 


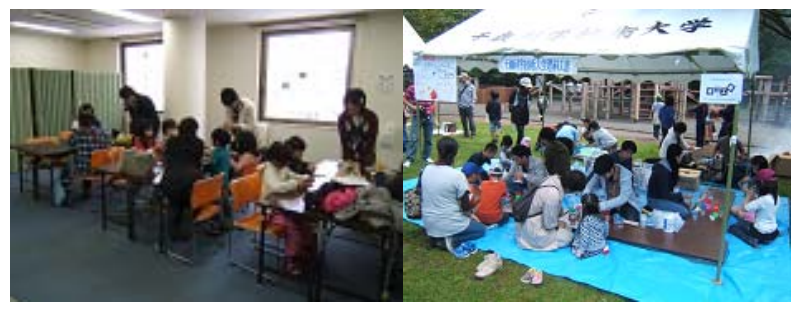

FIGURE V. ACTIVITIES IN RESPONSE TO INVITATIONS FROM LOCAL ORGANIZATIONS BOTH OUTDOORS AND INDOORS

\section{EDUCATIONAL EFFECTS OF THE ACTIVITIES}

Numerical analysis and/or evaluation of educational effects for the student members of the project teams, to be achieved through their involvement into the activities, are difficult. As the best effort, the author often asks some questions to the student members. Figs.VI shows some of the results obtained in October 2013 [4]. The number of the students who responded was 18. Specifically, several skills/abilities were listed and each of the student members was asked to pick up, among the list, any specific skills/abilities: (1) they thought obtained/improved; and (2) they realized lacking and necessary to obtain/improve, both through participation to the activities. The student members were allowed to make selections without limitation.
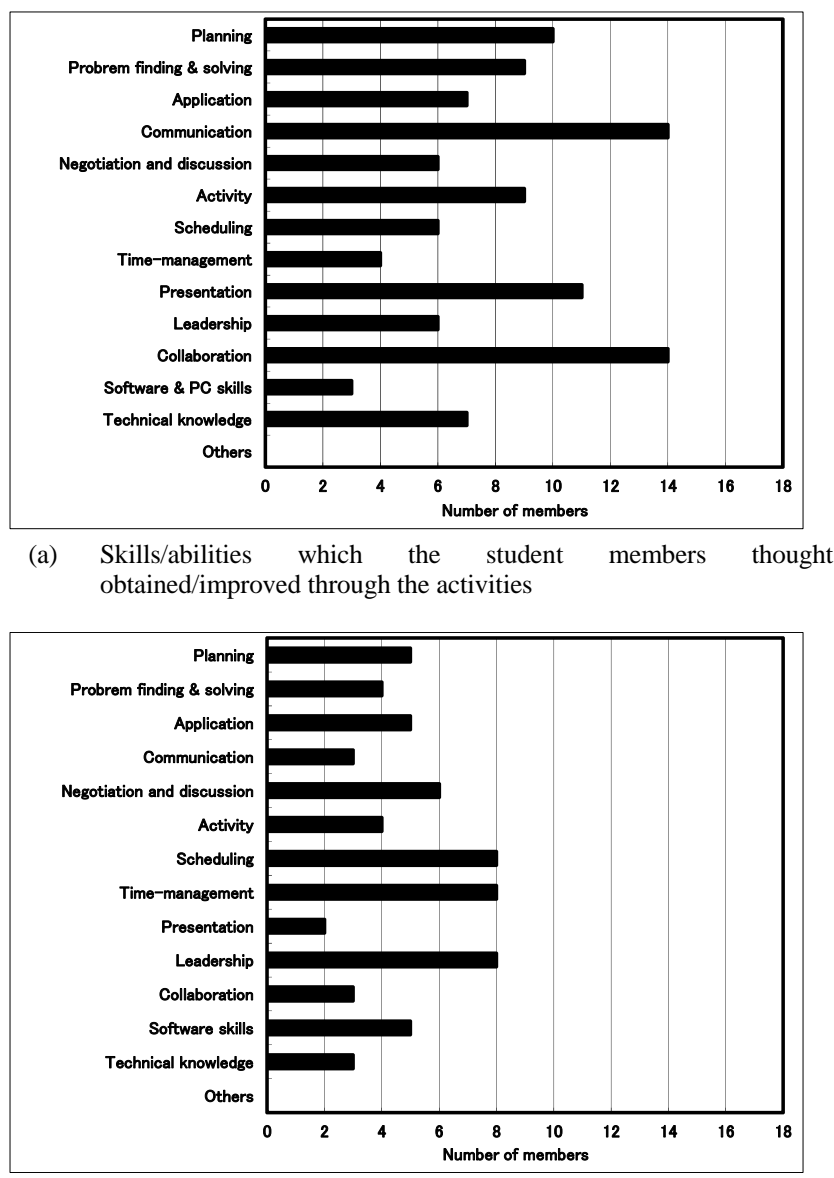

(b) Skills/abilities which the student members thought lacking and/or necessary to obtain/improve through the activities

\section{FIGURE VI. \\ RESPONSES OF STUDENT MEMBERS ABOUT} SKILLS/ABILITIES [4]

These results clearly indicate that the student members thought they obtained or improved certain skills/abilities such as communication skill, collaboration skill, presentation skill, planning skill, as well as problem finding \& solving skill. At the same time, they also realized certain skills/abilities were lacking and need to be obtained/improved. Such results were interesting because the activities of the student project team can actually provide the student members with opportunities for their career development.

\section{DISCUSSIONS}

\section{A. Faborable Effects of the Out-of-Carriculum Activities}

The results shown in the previous section indicate that the activities of this student project team can actually act as a certain scheme for the purpose of student education. Although investigation and analysis in detail have not yet been done, the author believes that one of the important factors of the activities exists in the fact that they are not included in the official university curriculum.

Specifically, the student members are involved in the activities not for intending to obtain credits nor improve their GPA scores, but instead simply based on their own interests. In other words, they are internally motivated. This is effective in the sense that each of them is likely to have the similar levels of motivation. Thus, collaboration effects can be enhanced.

In addition, the student members do not have to worry about their evaluation (scores) through the activities. Thus, they can challenge high-level targets or goals without being afraid of making failures.

It is also beneficial for teachers, because we also do not have to worry about making evaluation of each student member. It is also unnecessary to provide instructions and/or guidance in detail to the student members. They have to think and act by themselves, and further, they are required to analyze the current situations of the activities and make revisions if necessary. In other words, the student members are actually required to be actively involved into the activities. In that sense, the activities can act as a real active-learning type education scheme.

Another beneficial aspect as the out-of-curriculum activities is that the activities are independent from specific majors, grades, or genders. If the activities were included in the official curriculum, then the student members would have been limited within a certain group (such as at the same age/grade or majors). Rather, the actual members have various background, which is effective to cultivate collaboration abilities. Communication among the different grades is also encouraged, and especially for the students in upper grades, some chances for obtaining/improving leadership skills are provided.

\section{B. Other Faborable Aspects of the Specific Activities}

Apart from the out-of-curriculum aspect of the activities, their other important aspects are located in the fact that they are performing a large amount of activities in significantly various types in wide ranges, as mentioned earlier. The respective activities have their own specific aims and targets, audience 
size, as well as locations. For example, even for the science experimental class with the same topic, it has to be different when it is to be performed at local facilities outside schools from that to be performed within a class room at schools. This is because in the latter case, participant children are often likely to vary in their ages and degrees of their interests.

In order to realize participants' satisfaction in each case, it is necessary for the student members to make certain adjustments every time so as to realize successful outcomes. Thus, each of their activities provides the student members with actual Project-Based-Learning (PBL) style experiences.

\section{CONCLUSIONS}

The activities of the out-of-curriculum student project team "Rika-Kobo" has been introduced. This project team organized by university students has been actively engaged in science promotion activities in local region over 10 years, and they perform a large amount of activities in significantly various types in wide ranges.

Certain merits can be found in their out-of-curriculum aspect in terms of achieving certain educational effects for the student members.

Therefore, some emphasis should be placed in out-ofcurriculum activities to be performed by student members of a project team as favorable education schemes for the purpose of realizing real active-learning style education through real project-based-learning activities.

\section{REFERENCES}

[1] M. Hasegawa, "Physics and science education through project activities of university students and regional collaboration.”, 12th Asia Pacific Physics Conference (APPC12), no.F-PTu-1, July 2013, and included in JPS Conference Proceedings, Vol.1, pp.017016-1 - 017016-4, 2014.

[2] M. Hasegawa, "Roles and effects of activities of a student project team in engineering education for university students in lower grades." Proc. 2013 IEEE International Conference on Teaching, Assessment, and Learning for Engineering (TALE2013), no.140, pp.87-90, August 2013.

[3] M. Hasegawa, N. Okawa, S. Teshima and S. Tokumitsu, "Science education through activities of the student project team under regional collaboration”, Abstracts of International Union of Materials Research Societies - 15th International Conference in Asia (IUMRS-ICA 2014), no.F1-I28-003, August 2014.

[4] M. Hasegawa, "New education scheme for college students through outof-curriculum project activities”, Intl. Journal of Modern Education Forum (IJMEF), Vol.4, Issue 3, pp.120-123, November 2014.

[5] M. Hasegawa and S. Teshima, "Undergraduates investigation on how to effectively use tablet terminals in science experiment classes and engineering education through such investigation”, Proc. 2014 IEEE International Conference on Teaching, Assessment, and Learning for Engineering (TALE2014), session.2F, no.1, December 2014. 